\title{
Interview Prof. Lynda Gratton, London Business School
}

\section{Interview Question}

Rajnish Tiwari and Cornelius Herstatt emphasize the role of global innovation networks for frugal innovation. In your book "The Shift" you underline that "the speed at which the nature of work is changing is having an extraordinary impact on working lives everywhere". Do you think that frugal innovation is such a key driver that requires companies to rethink the way they are designing their organizational practices? If so, what are your recommendations to do so?

\section{Author: Prof. Lynda Gratton, London Business School}

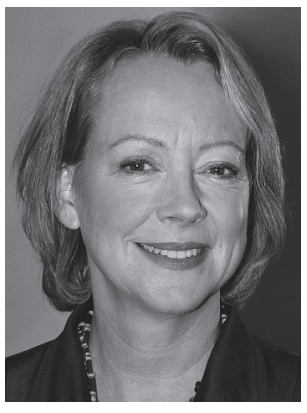

The emerging markets are creating extraordinary opportunities to innovate through low cost and high quality in both goods and services. The same is true in organizational practices. Take for example India that historically has a poor record of educating its children, a chaotic government and an impossible road and rail infrastructure. And yet the sub continent is currently producing some of the world's greatest companies, particularly in technology (e.g. Wipro, Infosys and TCS) and manufacturing (e.g. Mahindra \& Mahindra and Tata). It would seem that the harshness of the conditions are shaping innovation in a number of core organizational practices. A particular focus has been education, were all the large IT companies have built a plethora of innovations to reach out into their communities to actively engage in the education of millions of children through the design of curricula, the training of teachers and the provision of IT technology. As a consequence they are developing world-class competence in 'work ready skills'. These innovations are so fundamental that they are now being actively exported into the other markets these companies operate in, particularly those countries like the U.S. and the U.K. where youth unemployment and the skill gap is a significant challenge. This innovative capability can also be seen deep inside these companies. For example, in a country with a relatively poor pipeline of executive talent, Mahindra and Mahindra have created 'shadow boards' that encourage their most talented youngsters to work closely with senior executives. At TCS, the sheer scale of India and paucity of transport infrastructure has created a real push for virtual working. As a consequence, the company has developed some of the most advanced practices in the world in both collaborative technology and the creation of a culture that enables virtual working. Again, these organizational practices, honed in India, are now being exported to the many thousands of TCS project teams. We first saw 'frugal innovation' shape a whole generation of goods and services - now the same forces are also shaping a whole generation of organizational practices and processes.

Lynda Gratton is Professor of Management Practice at London Business School and founder and head of the Hot Spots Movement (www.hotspotsmovement.com) as well as the Future of Work Consortium (www.lyndagrattonfutureofwork.com), London, UK. 